\title{
Reasonability of development of agro-insurance in Russian Federation on the basis of mutual insurance
}

\author{
Irina Logvinova ${ }^{l}$, and Yury Rubin \\ Moscow University for Industry and Finance "Synergy", 127299, Leningradsky av., 80G, Moscow, \\ Russia
}

\begin{abstract}
Article deals with the justification of reasonability of agro insurance risk-management development in Russian Federation on the basis of mutual insurance. Nowadays this kind of insurance is carried out only by the commercial insurers, and thus are created conditions for the non-rational usage both private and government finance directing for the insurance premium. At the same time there is a successful practice of some developed countries and also Russian historical experience of mutual insurance of agricultural risks. The authors suggest to develop mutual insurance societies of agricultural risks not excepting the possibility of insurance of such kind of risks by the commercial insurers. It is pointed out that in RF mutual insurance societies for successful development will need the support of the state in the form of organizational and fiscal facilities. Development of mutual insurance societies of agricultural risks will prevent transformation of the part of the finance into the dividend for the owners of the insurance companies, and also activates the competition in the sector of agro insurance.
\end{abstract}

\section{Introduction}

In the modern Russia till recently agro insurance market was undeveloped. But in 2019 a significant growth took place.

The main reason for this the insurers consider coming into force from the 1 of March 2019 the changes in the Federal Law from 25 of July 2011 N 260-FZ "About the State Support in the Sphere of Agricultural Insurance and about the changes in the Federal Law about the development of Agricultural Sector". These changes concerned the organization of insurance of agricultural risks and became stimulus for development of this segment of insurance market. In particular, there was stated minimum size of unconditional franchise as $10 \%$ and increased its maximum from $30 \%$ till $50 \%$ for each agricultural crop. As a result, the insurers begin to propose more wide assortment of insurance products, and this allowed to meet better the needs of the policyholders - middle and small agro-producers. The changes in the practice of insurance according with the law mentioned above enable to meet better the needs of policyholders. It seems that such approach demonstrates attention of the state to the protection of wealth interests of the agro-producers by the mechanism of insurance, awareness of the need of using such mechanisms.

However, in this market segment there is a high degree of monopolization. Agricultural insurance products are offered by only 15 insurance companies. According to the Central

\footnotetext{
${ }^{1}$ Corresponding author: logir1@yandex.ru
} 
Bank, the share of the largest agricultural insurer - RSHB Insurance Company as of March 2020 is 41.2 percent in the agricultural insurance market, including insurance with state support - 38.4 percent [https://rg.ru/ 2020/03/30 / rynok-agrostrahovaniia-v-rossii-nachalvosstanavlivatsia.html].

It is also important to note that in the insurance market of the Russian Federation as a whole, the vast majority are commercial insurance companies. Mutual insurance organizations are represented by only 10 mutual insurance societies (hereinafter MIS). Only two of them have a license for agricultural insurance, and one of these companies is not conducting any activity yet [https://www.insur-info.ru/register/]. Meanwhile, in foreign countries (USA, Canada, Italy, etc.), mutual insurance is successfully used for insurance of such kind of risks.

The publications of Russian scientists discuss various aspects of the development of agricultural insurance. However, the use of mutual insurance is rarely mentioned. In our opinion, this topic deserves closer attention. In particular, it is necessary to show the positive consequences of the development of agricultural insurance in this direction.

\section{Materials and Methods}

The study presented in the article is based on the knowledge of the history of mutual insurance development, its usage for the insurance of various risks, in particular usage of mutual insurance for the insurance of agricultural risks in the various countries in modern conditions, as well as in the Russian Empire until 1918.

The study is based on statistical data that characterize the current state of the Russian market of agricultural insurance, in particular on the official data of Central Bank of the Russian Federation, the National Union of Agro Insurers of Russian Federation. Authors relied on the materials on the history of agricultural insurance in Russia before 1918, materials on the development of mutual insurance in Germany, the UK and several other countries; modern publications of Russian and foreign scientists.

In this article, mutual insurance is interpreted as a method of creation of insurance products that exists simultaneously with the method of self-insurance and the method of commercial insurance [1]. According to the method of creation of insurance products, which is the basis of activity of the actors of insurance business, such entities may be divided into two types - commercial insurance organization (hereinafter - CIO) and mutual insurance organizations (hereinafter - MIO) [1].

Positioning of mutual insurance as a method of creation of insurance products allows to understand better the essence of this method, its differences from the method of commercial insurance, to identify the advantages and disadvantages of each method, to show the reasonability of developing risk-management in agricultural insurance on the bases on mutual insurance.

\section{Results and discussion}

\subsection{Peculiarities of the use of profit in commercial and mutual insurance organizations}

Russian scientists note that today in the Russian Federation the agricultural insurance products are not used widely enough to address important socio-economic challenges on a national scale, in particular to provide insurance protection to farmers [2]. At the same time in Russia as in some other countries higher frequency and intensity of extreme weather events have increased farmers' risk exposure, which has increased the need for integrated risk management [3]. 
Currently agricultural insurance in the Russian Federation is provided by 15 insurance companies [http://www.naai.ru/o-soyuze/statisticheskie_svedeniya_/]. In 2019, the insurance premium accrued by all of these companies under agricultural risk insurance contracts amounted to 4376 million rubles. The amount of insurance payments under such contracts amounted to 519 million rubles for the same period, of which 357 million rubles were paid under contracts of the previous 2018 [http://www.naai.ru/osoyuze/statisticheskie_svedeniya_/].

Most insurance companies earn revenues from premiums (amounts paid by the purchaser of insurance products) and from investment income earned on the float (amounts collected as premiums and not yet paid out as benefits [4,5]. In conjunction with the insurance premium, the insurer receives resources for administrative expenses (such as the purchase of current assets necessary and insurance expenses) [6]. The financial assets remaining after the end of the year, not spent for these purposes and for formation of insurance reserves, are transformed into the profit of the insurance company. These funds came into disposal of the owners of the company-insurer. Direction of usage of profit are conditioned by the legislation, as well as by the economic logic and differs considerably in the frames of commercial insurance and the mutual insurance.

As it was shown above the overwhelming number of the companies conducting agro insurance in the RF commercial, i.e. using method commercial insurance. In this case, the directions of spending profit are determined by the shareholders of the company who are not the insured of this company. They invest in such a company in order to receive future dividends on invested capital. Therefore, as a rule, they decide to send a significant part of profit for the payment of dividends to shareholders. Some part may be directed to the development of the company.

Insurance companies engaged in agricultural risk insurance in the Russian Federation are engaged in several types of insurance at the same time. For example, the largest market participant of agricultural insurance - the company "Rosselkhozbank - Insurance" - is also conduct insurance of construction risks, cargo insurance, liability insurance and some other [ http://www.rshbins.ru/corporate client/ ]. In this regard, a situation arises in which the funds earned by a company in the agricultural insurance sector can be used to develop other types of insurance. In any case, these funds are unlikely to be used to reduce the size of the insurance premium in the future, i.e. the price of insurance. Only external circumstances, such as competition, can force a commercial insurer to use pricing methods to attract customers. If such external pressure is absent, he is not interested in lowering the prices of his insurance products.

Unlike commercial insurance, in mutual insurance, funds which were not used by the insurer to conduct business and insurance payments in accordance with the concluded agreements, cannot be distributed between the owners of the mutual insurance organization.

As it is known, in mutual insurance, policyholders simultaneously are the members of a mutual insurance organization and its co-owners [1]. They become co-owners of such an organization not in order to earn dividends, but in order to provide insurance protection for their wealth interests on the terms most suitable for them. In this regard, they are most interested not in receiving dividends, but in the best organization of insurance.

The decisions on the directions of expenditure of funds of a mutual insurance organization are made by the general meeting of policyholders or their representatives. In particular, such a meeting can make a decision about the direction of these financial assets to the insurance fund or for reduction of insurance premium for all or for the most honest policyholders of the insurance organization.

A negative point for insurers-members of a mutual insurance organization is the likelihood of formatting a situation in which they will have to make additional contributions so that the organization can fulfill all its insurance obligations. The most likely occurrence 
of such a situation in agricultural insurance may format as a result of natural circumstances. In such situations, a significant role can be played by the financial support of the state, provided for instance a gratuitous basis on conditions of interest-free repayment of debt over a long period.

In modern Russia, like in the US and some other countries the main instrument of state support is the submission of grants for payment of insurance premiums, which allows minimizing the cost of insurance for farmers [2]. Currently, the state subsidizes $50 \%$ of the insurance premium under agricultural risk insurance contracts. An important consequence of the introduction of a mutual insurance in this sector of the insurance market will be saving money paid as insurance premium on agricultural risk insurance contracts (both private and paid from the state budget). These funds will be spent more rationally. In mutual insurance companies the possibility of transformation of such funds in the dividend 's payable to the owners of insurance companies will be excluded.

\subsection{MIS of agricultural risks - the preferred direction for the development of mutual insurance in the agricultural insurance sector}

The issue of development in the Russian Federation of agricultural risks insurance on the basis of mutual insurance Russian scientists propose to solve, in particular, in the context of the organization of private -state partnership. One of the suggestions is to develop a mutual insurance of agricultural risks on the bases of mutual insurance societies by analogy with Zemsky mutual insurance, which developed in Russia from 1864 to 1918 [2].

However, a detailed acquaintance with this phenomenon of Russian history allows us to conclude that mutual insurance societies existed in the Russian Empire, but did not deal with agricultural risk insurance. These risks were insured in the system of mutual zemstvo insurance, the organization of which was different from mutual insurance societies [7].

The possibility of creating mutual insurance organizations to insure agricultural risks within a certain territory, as it was in Russia until 1918, in modern Russia seems impractical. The fact is that the zemstvo insurance was a specific form of insurance company, which had significant differences from a mutual insurance society, although it was based on the method of mutual insurance. The most significant difference was that the provincial zemstvo, that was the local self-government body, acted as the insurer. Such insurance, naturally, covered only those farms that were located on the territory of a particular province. Mutual zemstvo insurance operated within the boundaries of each province and did not compete with neighboring provincial insurers. Under zemstvo mutual insurance, the provincial zemstvo acted as the insurer. In each zemstvo, a business insurance office was specially created, which was maintained at the expense of the zemstvo, and this gave a certain saving of funds collected as insurance premiums.

It is known, the zemstvos were local self-government bodies. The obligation to insure certain risks on the basis of the mutual insurance method was assigned to the zemstvos by the state. In this case the state does not subsidize insurance premiums, paid by insurers.

For modern Russia, such an organizational model is hardly acceptable. The local self government bodies do not have the organizational and material resources, and necessary specialists for successful implementation of such a model. Also in modern Russia it is inexpedient to create mutual insurance organizations on a territorial basis, limiting their activities to a certain territory. While small and medium-sized agricultural producers predominated in Russia until 1918, now large agricultural holdings also operate. When manufacturers of various scales are united in a mutual insurance organization, it may be more difficult for small farmers to defend their interests.

It should also be noted that over the years of the command economy in the USSR, economic knowledge about the organization of mutual insurance in general and mutual 
zemstvo insurance in particular was almost completely lost. This circumstance is an important factor that makes it difficult to create legislative conditions that meet the economic nature of mutual insurance in general, and a model similar to mutual zemstvo insurance in particular.

Therefore, it is advisable, in our opinion, to set up mutual insurance societies as a model for the development of mutual insurance for agricultural risk management. This is the only legal organizational form provided by modern Russian legislation for mutual insurance organizations. Such a development path does not require the development of a fundamentally new legislative document, and can be carried out on the basis of the already existing Federal Law of the Russian Federation of November 29, 2007 N 286-FZ "On Mutual Insurance".

Great peculiarity of conditions of mutual insurance development in the modern insurance market of the Russian Federation is complete domination of commercial insurance companies, which consider the appearance of mutual insurance companies as extremely undesirable phenomenon for them and use their influence to encourage the administrative actions against their appearance. In 2008 mandatory licensing of MIS's was introduced. None of the mutual insurance societies existed at that time were able to obtain a license, while the licensing authority did not give a clear explanation of the reasons for the refusal of a license.

In our opinion, a purposeful work aimed at the state stimulation of creation of mutual insurance societies of agricultural risks is required. Such a problem can be solved by facilitating and increasing the transparency of the licensing process of such organizations, providing them with tax benefits, and also allocating them initial capital at the expense of the state budget. This capital can be released free of charge, or on the terms of an interest-free loan with a long maturity and period of repayment for 5 or 10 years in condition that the MIS deals exclusively with the insurance of agricultural risks.

For the development of mutual agricultural insurance in the Russian Federation, a lot of preparatory work is necessary, first of all, an explanation of all the features of this type of insurance, training of specialists with the competencies necessary for working in such organizations. It seems that at first it was necessary to use certain administrative resources to oversee the processes of creating and starting the practical activities of such societies.

Small businesses are increasingly struggling with the growing pressure of big business and, in order to survive, smallest businesses are forced to cooperate with each other [8]. The agricultural sector is not the exception to this rule. In this regard, it is preferable to unite insurers of approximately the same scale of activity, that is, the creation of mutual insurance societies for large agricultural holdings, medium-sized agricultural producers and small farmers. Obviously, the amount of risks that agricultural producers insure is predetermined by their financial capabilities. From this perspective, the union of policyholders having approximately the same capability allows within society create insurance products which can meet the needs of its member-policyholders better both in terms of risks to be insured, and in terms of the insurance premiums' size.

Financial sustainability of mutual insurance companies should be provided by means of compulsory reinsurance, as well as by other state measures. Such measures, for example, may be the provision of interest-free loans to companies of mutual insurance of agricultural risks at the expense of federal or local budgets with a long repayment term. Also, such MISs can be obliged to invest a certain part of their funds in reliable assets that bring a small but stable income (for example, it can be reliable securities or real estate objects to receive income from their lease).

\subsection{Development of competition in the agricultural insurance sector as a result of the emergence of mutual insurance societies}


The development of the agricultural insurance sector in the Russian Federation by stimulating the creation of mutual insurance societies of agricultural risks implies that such companies will not have monopoly rights either within a certain territory or within certain types of insurance. There emergency in the market will create new directions of competition - between MISs and commercial insurance companies (see Fig.1). This will form additional incentives for the development of agro-insurance market.

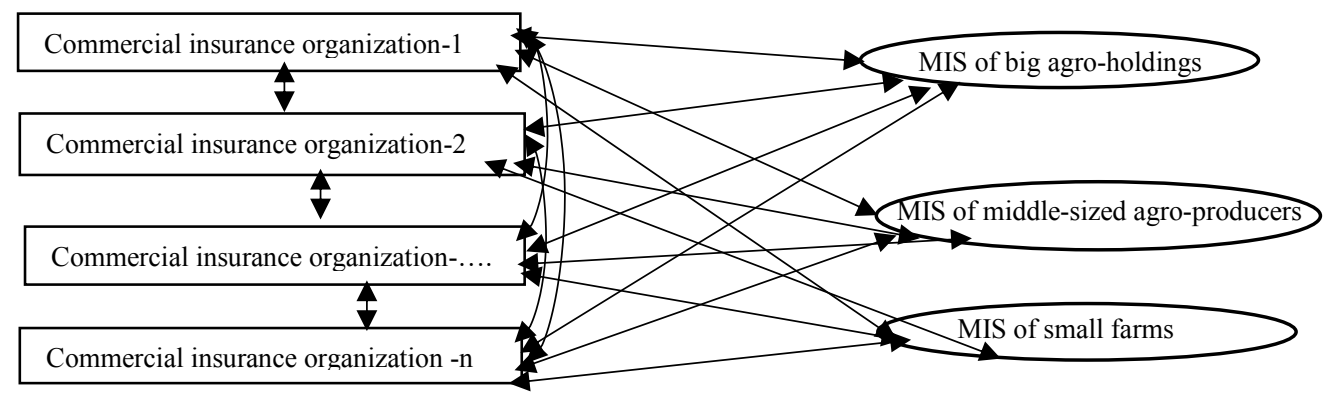

Fig. 1. Competition directions on the agro-insurance market in presence of MISs.

So, commercial insurance companies will be forced to cut prices to attract more clients. Currently, in the Russian Federation in the sector of agricultural insurance are the only commercial insurance organizations and prices formats without the influence of the mutual insurance organizations. Meanwhile, the emergency of MIS changes the situation. A striking example of such a change can be found in the history of the development of fire insurance in the Russian Empire. At the beginning of the last third of the XIX century, prices for such insurance increased for about a third. This happened as a result of the fact that eight joint-stock insurers, having leading positions in the Russian fire insurance market, signed a price convention. In response, urban homeowners began to create urban fire insurance mutual societies, which set lower prices for their insured members than commercial companies. As a result, in those towns where fire MISs began to operate, joint-stock insurers who signed the convention reduced the price of similar insurance products.

Considering competition as aT ordered interaction in professional business [9, 10], we can confidently say that the emergence of mutual insurance companies in the sector of agricultural insurance cannot lead to the complete exclusion of commercial insurers. Firstly, it will be beneficial for policyholders to share their risks between commercial and mutual insurance companies. This distribution will allow to neutralize the disadvantages of each method of creation of insurance products. Secondly, mutual insurance implies compulsory reinsurance, and such reinsurance MISs can acquire in commercial insurance organizations.

Market interaction of commercial and mutual insurance organizations is a sign of a developed insurance market, in which the policyholder can find a wide range of insurance products and choose those that are best suited to his needs and financial capabilities.

\section{Conclusions}

The conduct of business, including business practices, is closely linked with jurisdictions' tradition, culture, legal regime and the degree of development of the insurance sector [6]. This is fully can be applied to the implementation of the insurance business in the agricultural insurance sector of the Russian Federation. The absolute predominance of commercial insurance organizations here is explained by the fact that knowledge of the theory and practice of mutual insurance was, unfortunately, lost in the USSR, because the economic nature of this method of creating of insurance products is incompatible with the administrative command economy. 
However, in modern conditions there is a real need for the application of methodmutual insurance for insurance of agricultural risks. The use of this method in the conditions of the Russian Federation is reasonable because it makes possible better take into account the interests of policyholders in different insurance products; reduce the amount of the insurance premium in agricultural insurance, reduce the amount of finance transformed into the dividends paid to owners of commercial insurers; strengthen competition in the sector of agricultural insurance, which will contribute to a more diverse range of insurance products both in terms of price and in terms of the set of insurable risks .

\section{References}

1. I.L. Logvinova, Mutual Insurance as Method of Insurance Products' Creation in Russian Economy. (2010)

2. A.O. Inshakova, M.S. Uskova, V.V. Dolinskaya, E.E. Frolova, Espacios, 39 (28), (2018)

3. J. Cordier, F. Santeramo, EuroChoices, (2019)

4. R.S. Barr, K.A Killgo, T.F. Siems, S. Zimmel, Managerial Finance, 28 (8), 3-25 (2002)

5. R.A. Cole, J.W. Gunther, Federal Reserve Bulletin, 81, 1-15 (2002)

6. L. Tsvetkova, T. Yurieva, L. Orlaniuk-Malitskaia, T. Plakhova, Montenegrin Journal of Economics, 15 (3), 189-204 (2019)

7. I.L. Logvinova, Mutual insurance in Russia: peculiarities of evolution, Moscow, (2009)

8. A.A. Tsyganov, A.D. Yazykov, Y.V. Gryzenkova, Journal of Applied Economic Sciences, 13 (6), 1519-1525 (2018)

9. Y. Rubin, M. Lednev, D. Mozhzhukhin, Journal of Entrepreneurship Education, 22 (6) (2019)

10. Y. Rubin, M. Lednev, D. Mozhzhukhin, Vysshee Obrazovanie v Rossii 28 (1), 21-33 (2019) 